\title{
Assessment of tantalum nanoparticle-induced MC3T3-E1 proliferation and underlying mechanisms
}

\author{
Chengrong Kang ${ }^{1} \cdot$ Yudong Wang ${ }^{1} \cdot{\text { Liang } \mathrm{Li}^{1} \cdot \text { Zhangwei }^{1}{ }^{1} \cdot \text { Qianbing Zhou }}^{1} \cdot$ Xuan Pan $^{1}$
}

Received: 24 April 2020 / Accepted: 6 October 2021 / Published online: 23 October 2021

(C) The Author(s) 2021

\section{Abstract}

Objective In our previous study, tantalum nanoparticle (Ta-NPs) was demonstrated to promote osteoblast proliferation via autophagy induction, but the specific mechanism remains unclear. In the present study, we will explore the potential mechanism.

Methods Ta-NPs was characterized by transmission electron microscopy, scanning electron microscopy, dynamic light scattering, and BET specific surface area test. MC3T3-E1 were treated with 0 or $20 \mu \mathrm{g} / \mathrm{mL}$ Ta-NPs with or without pretreatment with $10 \mu \mathrm{M}$ LY294002, Triciribine, Rapamycin (PI3K/Akt/mTOR pathway inhibitors) for $1 \mathrm{~h}$ respectively. Western blotting was used to detect the expressions of pathway proteins and LC3B. CCK-8 assay was used to assess cell viability. Flow cytometry was used to detect apoptosis and cell cycle.

Results After pretreatment with LY294002, Triciribine and Rapamycin, the p-Akt/Akt ratio of pathway protein in Triciribine and Rapamycin groups decreased $(P<0.05)$, while the autophagy protein LC3-II/LC3-I in the Rapamycin group was upregulated obviously $(P<0.001)$. In all pretreated groups, apoptosis was increased (LY294002 group was the most obvious), G1 phase cell cycle was arrested (Triciribine and Rapamycin groups were more obvious), and MC3T3-E1 cells were proliferated much more $(P<0.01, P<0.001, P<0.05)$.

Conclusion Pretreatment with Triciribine or Rapamycin has a greater effect on pathway protein Akt, cell cycle arrest, autophagy protein, and cell proliferation but with inconsistent magnitude, which may be inferred that the Akt/mTOR pathway, as well as its feedback loop, were more likely involved in these processes.

\section{Graphical Abstract}

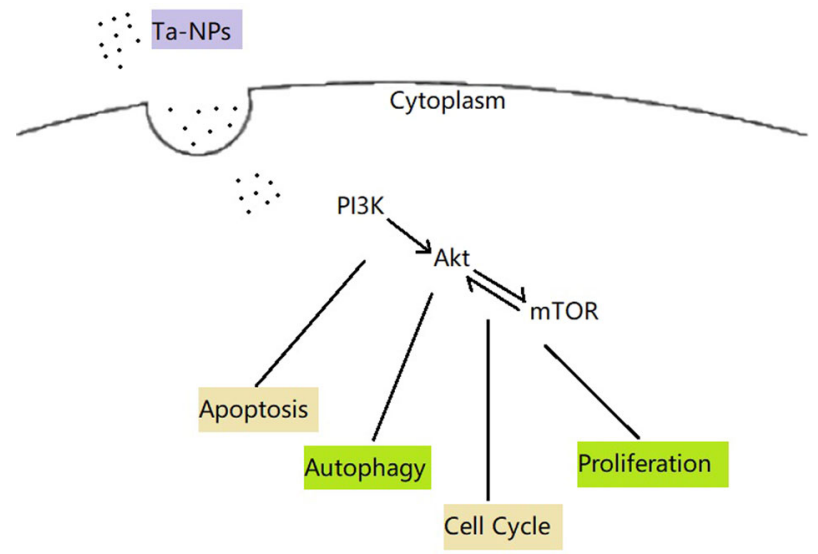

These authors contributed equally: Chengrong Kang and

Yudong Wang.

Xuan Pan

124779994@qq.com
1 Department of Stomatology, The First Affiliated Hospital of Guangdong Pharmaceutical University, Guangzhou 510080, China 


\section{Introduction}

Tantalum has been widely used in medical fields for its excellent biocompatibility, anticorrosive effects, and superior strength. Tantalum-based coatings can promote bone formation, and improve healing and fusion efficacy, especially for patients afflicted by diabetes [1-3]. With the emergence of nanotechnology, nanostructured tantalum, such as tantalum nanoparticles (Ta-NPs), nano-Ta film, and Ta porous scaffolds, have been widely used in dentistry and orthopedics to create an interfacial layer to promote stable cellular adhesion, proliferation, and differentiation [4-7].

Many scholars proposed that tantalum nanotube arrays could enhance cellular adhesion, proliferation, and differentiation [8]. Hierarchical structure features, combined with micron and nanoscale tantalum, were found to have possessed higher surface hydrophilicity and enhanced resistance to corrosion. It facilitated enhanced cell adherence and spreading during initial culture stages (up to $24 \mathrm{~h}$ postinitiation) and enhanced cell proliferation, maturation and mineralization within 14 days post-initiation of the culture period $[9,10]$. In addition, another in vitro and in vivo study came to similar conclusions that hierarchical micro-nano surfaces significantly increased cellular activities, the boneto-implant contact area, and newly derived bone volume [11]. These findings could facilitate a fascinating strategy for achieving fast and stable fixation.

Porous tantalum, combine with the dual advantages of hierarchical micro-nano tantalum surfaces and bone trabecularlike porous structures, promoted cell adhesion and proliferation and showed good biocompatibility and osteo-compatibility in vitro as well as in vivo [12,13]. Moreover, porous tantalum combined with bone marrow stromal stem cells (BMSCs) and bone marrow mesenchymal stem cells (BMMSCs) had even higher efficacies upon osteogenesis $[14,15]$.

Ta-NPs could promote osteoblast proliferation in low concentrations $(12.5 \mu \mathrm{g} / \mathrm{mL})$, but inhibit proliferation in high concentrations ( $\geq 25 \mu \mathrm{g} / \mathrm{mL}$ ). This kind of phenomenon was found to be related to autophagy and oxidative stress [16]. In another study, autophagy was proved to be involved in Ta-NPs induced osteoblast proliferation and played a promoting effect [7]. However, this article had no further study on the potential signal pathway.

The PI3K/Akt/mTOR signaling pathway is a classical pathway that has been widely studied. It plays a key role in transcription, translation, metabolism, and regulates a series of cellular processes, including cell proliferation, the cell cycle, autophagy, apoptosis, DNA repair, and so on [17-19]. Therefore, the PI3K/AKT/mTOR signaling pathway has increasingly emerged as a target for disease therapeutic treatments. In many types of cancer treatments, pathway inhibitors and analogs are used to intervene in the PI3K/Akt/ mTOR pathway, and thus regulate autophagy and other cellular processes, as well as influence tumor growth [20, 21]. But the drug resistance was the trickiest problem in cancer treatments. Studies have shown that dynamic feedback loops or cross-links between PI3K/Akt/mTOR itself or other related pathways were associated with the drug resistance [22-25].

Based upon these findings, we sought to verify whether the PI3K/Akt/mTOR signaling pathway and its feedback loop participated in Ta-NPs induced autophagy and osteoblast proliferation.

\section{Materials and methods}

\subsection{Chemicals and chemical suspensions}

Ta-NPs were purchased from Sigma-Aldrich (St Louis, MO, USA; product number 593486). Antibodies against LC3B, (p-)PI3K, (p-)Akt, (p-)mTOR, $\beta$-actin, and LY294002 (PI3K inhibitor, LY), Triciribine (Akt inhibitor, API) were all purchased from Cell Signaling Technology (CST, Beverly, MA, USA). Rapamycin (mTOR inhibitor, Rapa) was purchased from Sigma-Aldrich. The Annexin-VFITC apoptosis detection kit was purchased from Thermo Fisher Scientific (USA). Cell Counting Kit-8 (CCK-8, Dojindo, Japan) assays were used to evaluate measures of cell viability.

Ta-NPs were characterized by transmission electron microscopy (TEM, Mic JEM-1011, JEOL, Japan), scanning electron microscopy (SEM, Nova Nano 430, FEI, Finland), and dynamic light scattering (DLS). Ta-NPs suspension was prepared as described in the previous study [7]. LY, API, and Rapa were dissolved according to the manufacturer's instructions to form stock solutions which were frozen at $-20^{\circ} \mathrm{C}$ until further use. Upon use, stock solutions were diluted to working concentrations with $\alpha$-MEM as needed.

\subsection{Cell treatment}

MC3T3-E1 mouse osteoblasts (Cell Bank of Shanghai Institute of Life Sciences, Chinese Academy of Sciences, China) were cultured in 6-well plates at a density of $1 \times 10^{4}$ cells/well with $2 \mathrm{~mL}$ of $\alpha$-MEM or were cultured in 96-well plates at a density of $1 \times 10^{3}$ cells/well with $100 \mu \mathrm{L}$ of $\alpha$ MEM (for CCK-8 assay only) for $24 \mathrm{~h}$ to allow for cell adherence. Next, cells were treated with 0 or $20 \mu \mathrm{g} / \mathrm{mL}$ TaNPs for another $24 \mathrm{~h}$ with or without $10 \mu \mathrm{M}$ of LY, of API, or of Rapa pretreatment for $1 \mathrm{~h}$ respectively.

\subsection{Measures of protein expression via Western blotting}

At predetermined time steps, we thrice rinsed cells with PBS and then lysed them with lysis buffer (Whole Cell 
Lysis Assay, KeyGEN, China) for 30 min on ice. Next, all cell lysates were collected and centrifuged at $10,000 \mathrm{~g}$ for $10 \mathrm{~min}$ at $4{ }^{\circ} \mathrm{C}$. We next collected supernatants and then quantified constituents using BCA Protein Quantitation Assays (Beyotime, China). Equivalent amounts of lysate proteins from each sample were loaded onto sodium dodecyl sulfate-polyacrylamide gels and were then electrophoretically transferred to polyvinylidene fluoride membranes (Merck Millipore, Billerica, MA, USA). Transferred membranes were then thrice rinsed ( 5 min each rinse) with $1 \times$ TBS containing $0.05 \%$ Tween-20 (TBST) and were then blocked with $5 \%$ nonfat milk in TBST for $30 \mathrm{~min}$ at room temperature. Next, membranes were incubated with primary antibodies against p-PI3K, PI3K, p-Akt, Akt, p-mTOR, mTOR, LC3B, and $\beta$-actin (1:1000, rabbit antibodies) overnight at $4{ }^{\circ} \mathrm{C}$. We then washed the membranes with TBST, incubated with a horseradish peroxidase-conjugated secondary antibody (1:2000, anti-rabbit antibodies) for $1 \mathrm{~h}$ at room temperature, and thrice washed them with TBST. Finally, antibody-bound membranes were detected using ECL Blotting Detection Reagent (Pierce, USA) and the grayscale values for protein bands were analyzed using Image Lab Software (Bio-Rad, USA).

\subsection{Cell viability by CCK-8 assay}

At predetermined time steps, cell plates were thrice washed with PBS and were then added into $100 \mu \mathrm{L}$ of fresh $\alpha$-MEM and $10 \mu \mathrm{L}$ of CCK- 8 reagent. After co-culture for $2 \mathrm{~h}$, the absorbance of the supernatant was quantified at $540 \mathrm{~nm}$ using a multi-well plate reader (Multiskan GO, Thermo Scientific, USA). Next, we determined the relative viability of cells using the following formula: relative viability $=[(\mathrm{As}-\mathrm{Ab}) /$ $(\mathrm{Ac}-\mathrm{Ab})] \times 100 \%$, where As is the experimental optical density (OD), Ac is the control OD, and Ab is the blank OD. At least 5 wells per treatment group and experimental conditions were examined in 3 independently replicated experiments.

\subsection{Apoptosis by flow cytometry}

At indicated time steps, cell mediums were carefully removed and preserved for later assessment. Cells were thrice rinsed with PBS, were digested with trypsin (without EDTA), and were then collected by centrifugation (1000 rpm, $5 \mathrm{~min}$ ). Next, cells were re-suspended in PBS and then centrifuged twice $(1000 \mathrm{rpm}, 5 \mathrm{~min})$ to wash thoroughly. The retained cell mediums described above were added before the final centrifugation. Then, we added $100 \mu \mathrm{L}$ of pre-cooled binding buffer to suspend the cells, added $5 \mu \mathrm{L}$ of Annexin $\mathrm{V}$, added PI, and gently mixed samples for $20 \mathrm{~min}$ at room temperature without light. Finally, cells were re-suspended in $400 \mu \mathrm{L}$ of pre-cooled binding buffer and were preserved without light at $4{ }^{\circ} \mathrm{C}$.

\subsection{Cell cycle by flow cytometry}

At indicated time steps, cells were digested by trypsin and then centrifuged for $5 \mathrm{~min}(1000 \mathrm{rpm})$, then were washed twice with PBS and finally collected by centrifugation (1000 rpm, $5 \mathrm{~min}$ ). Next, we fixed cells with $70 \%$ ethanol at $4{ }^{\circ} \mathrm{C}$ for $12 \mathrm{~h}$ and washed twice with PBS to remove residual ethanol. Then, $100 \mu \mathrm{L}$ RNase A was added and samples were submerged in a warm bath for $30 \mathrm{~min}$ at $37^{\circ} \mathrm{C}$, followed with $30 \mathrm{~min}$ of incubation with $400 \mu \mathrm{L}$ of DNAbinding dye propidium iodide (PI) at $4{ }^{\circ} \mathrm{C}$ without light. Finally, we used flow cytometry (BD Biosciences, Franklin Lakes, NJ, USA) to facilitate detections of cell cycle phases based upon measures of DNA content.

\subsection{Statistical analyses}

Quantitative results were presented as the mean \pm standard deviation (SD) and were normalized using one-way analysis of variance (ANOVA). Those data that passed the normality tests were analyzed with the least significant difference test (LSD); those data that did not pass the normality tests were analyzed with a Dunnett's test. All analyses were conducted using SPSS 22.0 software (SPSS Inc., Chicago, IL, USA). Statistical measures were considered significant when $P$ values $<0.05$.

\section{Results}

\subsection{Characterization of Ta-NPs}

Ta-NPs were primarily spherical with primary diameters of $8-15 \mathrm{~nm}$ and hydrodynamic sizes of $292 \mathrm{~nm}$ (Fig. 1) [7]. In addition, the specific surface area for Ta-NPs $=78.19 \mathrm{~m}^{2} / \mathrm{g}$.

\subsection{Protein expression}

Western blotting was used to detect the expression levels of pathway proteins and autophagy protein LC3B. Compared with Ta-NPs alone treated group, the pathway protein P-Akt /Akt was downregulated in the API and Rapa pretreated groups $(P<$ 0.05 ), and the autophagy protein LC3-II/LC3-I was further upregulated in the Rapa pretreated group $(P<0.001)$ (Fig. 2).

\subsection{Cell viability by CCK-8 assay}

The CCK-8 assay was used to measure cell viability (Fig. 3). Results indicated that Ta-NPs treatment could promote the proliferation of MC3T3-E1. Moreover, the pretreatment of LY, API, or Rapa all significantly further increased the cell viability $(P<0.01, P<0.001, P<0.05$, respectively), especially the API pretreated group. 

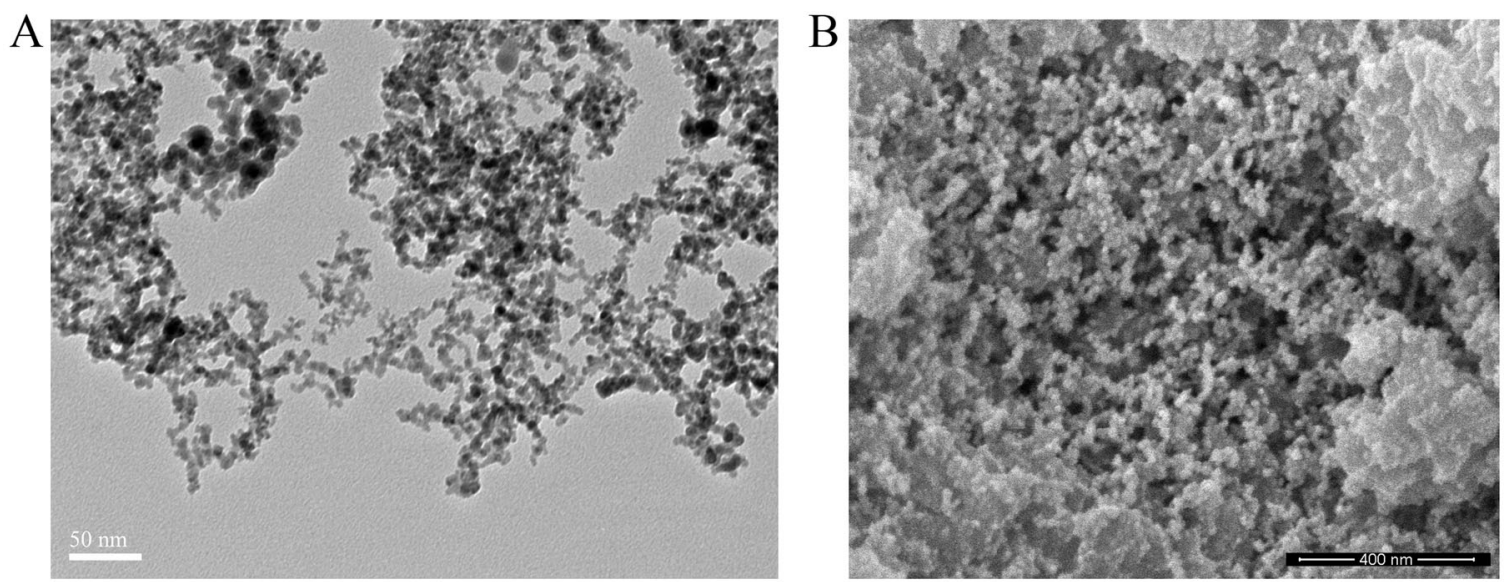

C

Size Distribution by Intensity

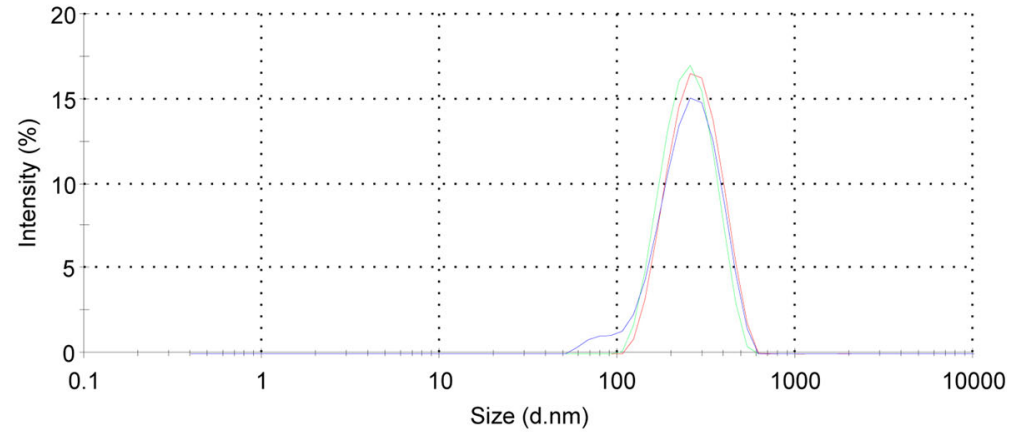

Record 1: nano-ta 1

Record 2: nano-ta 2

Record 3: nano-ta 3

Fig. 1 Characterization of Ta-NPs. TEM (A) and SEM (B) images showed primarily spherical shapes. Magnification: $\times 200,000$. C DLS measurement
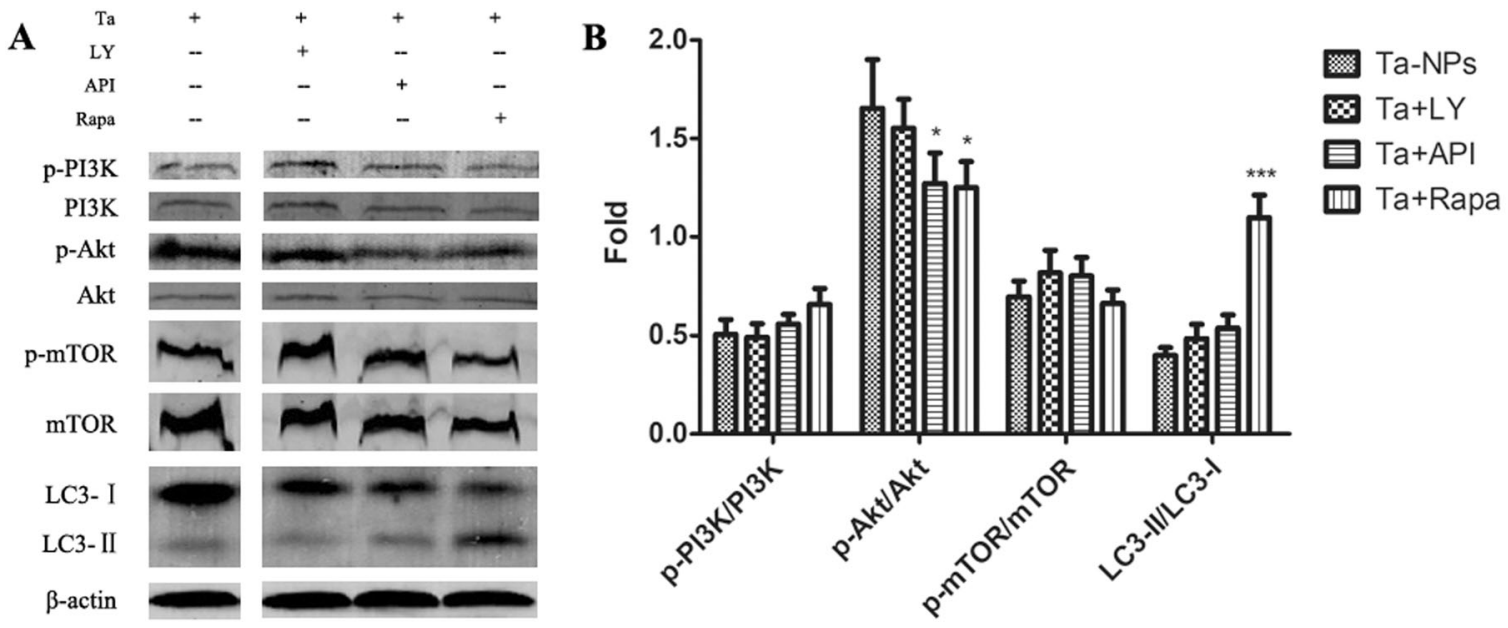

Fig. 2 Expression of pathway proteins and autophagy protein (A) and quantified in column diagram (B). MC3T3-E1 was pretreated with or without $10 \mu \mathrm{M}$ of LY, API, or Rapa respectively for $1 \mathrm{~h}$ followed with $20 \mu \mathrm{g} / \mathrm{mL}$ Ta-NPs treatment for another $24 \mathrm{~h}$. $* P<0.05$, $* * * P<0.001 \mathrm{vs}$. Ta-NPs alone treated group 


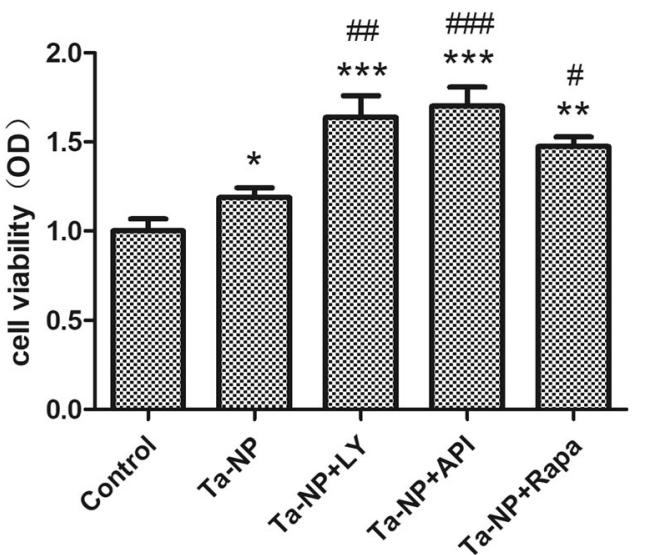

Fig. 3 Cell viability. MC3T3-E1 was pretreated with or without $10 \mu \mathrm{M}$ of LY, API, or Rapa respectively for $1 \mathrm{~h}$ followed with $20 \mu \mathrm{g} / \mathrm{mL}$ TaNPs treatment for another $24 \mathrm{~h}$. At least 5 wells per condition were examined in 3 independently replicated experiments. $* P<0.05$, $* * P<$ 0.01 , *** $P<0.001$ versus control group; ${ }^{\#} P<0.05,{ }^{\# \#} P<0.01,{ }^{\# \#} P<$ 0.001 vs. Ta-NPs alone treated group

\subsection{Cell apoptosis by flow cytometry}

Having detected the autophagy and proliferation of MC3T3-E1, we further explored the apoptosis and cell cycle using flow cytometry. Results indicated that the pretreatment of LY, API, and Rapa all upregulated cell apoptosis from a level of $0.33 \%$ in the Ta-NPs alone treated group to levels of $4.92 \%, 3.10 \%$, and $3.50 \%$, respectively (Fig. 4).

\subsection{Cell cycle by flow cytometry}

Finally, we assessed the dynamics of cell cycle phases based upon sample DNA content (Fig. 5). Results indicated that the pretreatment of LY, API, and Rapa all increased the proportions of cells in the G1 phase and decreased cells in the S and G2 phases, especially for the API and Rapa pretreated groups.

\section{Discussion}

In our previous research, we proved that autophagy played a positive role in Ta-NPs induced osteoblast proliferation. In this study, we further explore the mechanism involved. The Western blotting findings indicated that only the level of pAkt/Akt in the API and Rapa pretreated group was lower than that in the Ta-NPs treated group. Meanwhile, the autophagy protein LC3-II/LC3-I in Rapa pretreated group was further upregulated. Did only the Akt participate? And why was the p-Akt/Akt expression in Rapa pretreated group also downregulated? Was there a feedback loop between mTOR and Akt in Ta-NPs treated MC3T3-E1?
The mTOR is a central regulator of cell growth and metabolism and is available in two complex forms: mTORC1 and mTORC2. mTORC1 is sensitive to rapamycin and its function is tightly regulated by PI3K/Akt; mTORC2 was found to have been indirectly inhibited by rapamycin-induced ROS [26, 27]. Moreover, mTORC1 is involved in multiple feedback loops [28-31], including the negative feedback loop between mTORC 1 and Akt. Activated mTORC1 could feedback inhibit Akt phosphorylation at Ser473 [31, 32]. mTORC2 is also involved in some feedback loops including a positive feedback loop between mTORC2 and Akt [27, 33, 34]. The positive mTORC2-Akt feedback loop has been revealed as follows: After activation of upstream PI3K, PDK1 activates Akt by way of phosphorylation of Thr308. The partially activated Akt then phosphorylated Sin 1 at T86 and enhanced mTORC2 kinase activity, that ultimately led to feedback phosphorylation of Akt Ser 473. Finally, this resulted in the full activation of Akt [35].

Rapamycin is the popular mTOR inhibitor and autophagy inducer. Rapamycin could simultaneously act on mTORC 1 and mTORC 2 and playing completely different roles according to the action time and concentration. Acute inhibition (for $1 \mathrm{~h}$ ) increased insulin signaling and glucose uptake, while chronic inhibition (for 24-48 h) induced insulin resistance and impaired insulin-mediated glucose uptake [22, 36]. Similarly, different concentrations of rapamycin resulted in a biphasic effect. Rapamycin in low concentration $(10 \mathrm{nM})$ increased the Akt and ERK phosphorylation through a mTORC1-dependent negative feedback loop, high dose of rapamycin $(1000 \mathrm{nM})$ inhibited the Akt and ERK phosphorylation via the mTORC2 mediated positive feedback loop [37]. In the present study, the action time and concentration of rapamycin were $1 \mathrm{~h}$ and $10 \mu \mathrm{M}$. Thus, rapamycin may act more on mTORC2 and the positive feedback loop between mTORC 2 and Akt may play a leading role. This may explain to some extent that the p-Akt/Akt level reduced only in API and Rapa pretreated group and the LC3-II/LC3-I upregulated in Rapa pretreated group. Published research has indicated that mTORC2 was tightly associated with the development of the cell cycle through an Akt-dependent manner [37]. As shown in the present study, high doses of rapamycin inhibited Akt phosphorylation and caused cell cycle arrest in the G1 phase, especially in the API and Rapa pretreated group. The two-way feedback loop in that rapamycin leads to Akt and ERK activation at low concentrations, whereas lead to Akt and ERK inhibition at high concentrations may probably offer an anti-cancer therapy strategy. Therefore, these findings implied that the Akt/mTOR 
Fig. 4 Cell apoptosis. MC3T3E1 was pretreated with or without $10 \mu \mathrm{M}$ of LY, API, or Rapa respectively for $1 \mathrm{~h}$ followed with $20 \mu \mathrm{g} / \mathrm{mL}$ Ta-NPs treatment for an additional $24 \mathrm{~h}$
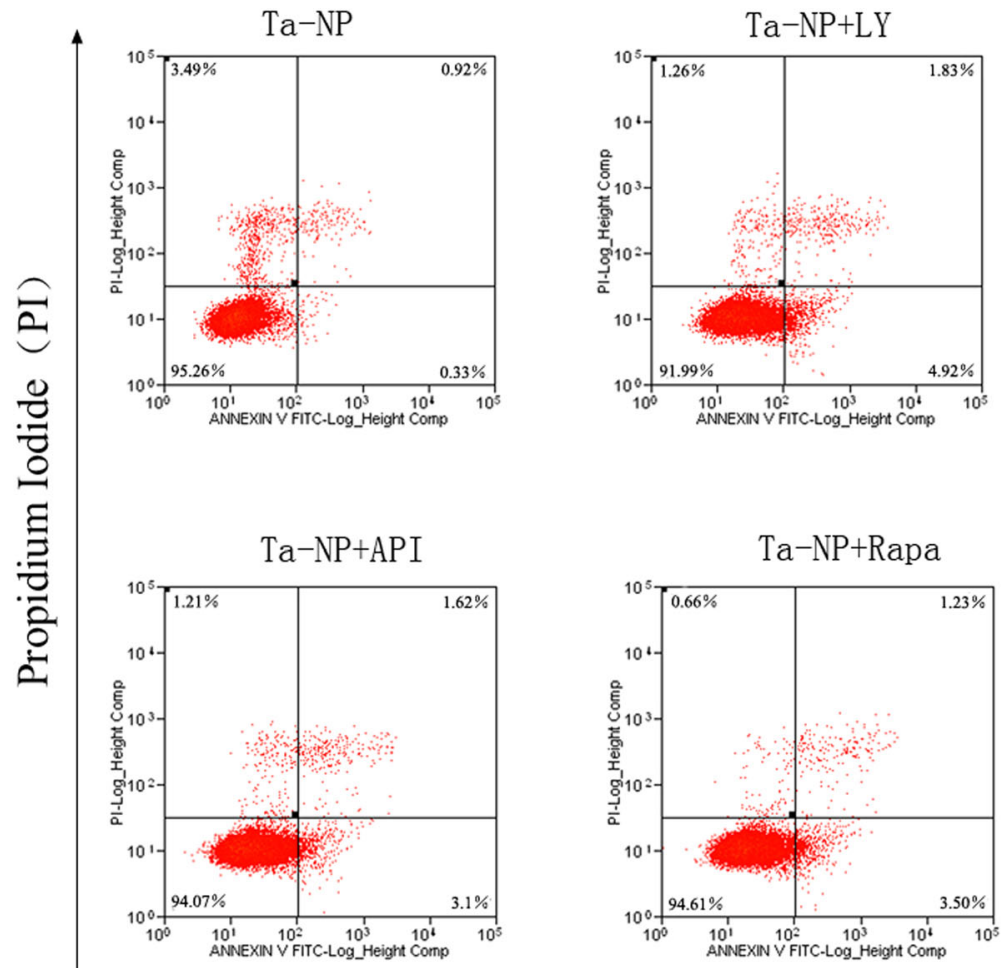

Annexin V-FITC
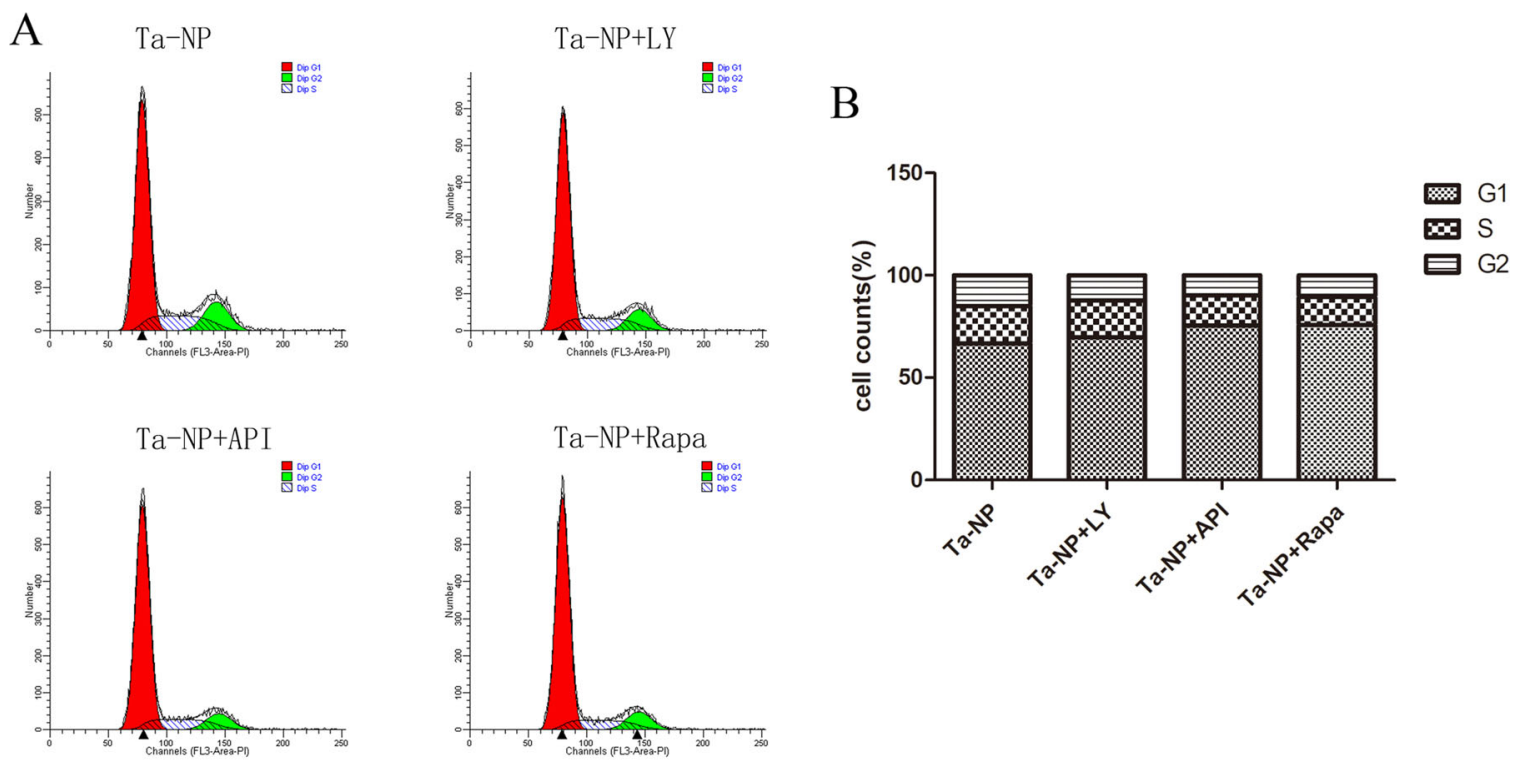

Fig. 5 Cell cycle in coordinate diagram (A) and quantified in colume diagram (B). MC3T3-E1 was pretreated with or without $10 \mu \mathrm{M}$ of LY, API, or Rapa respectively for $1 \mathrm{~h}$ followed with $20 \mu \mathrm{g} / \mathrm{mL}$ Ta-NPs treatment for an additional $24 \mathrm{~h}$

signaling pathway and its feedback loop participated in the cell regulation of Ta-NPs treated MC3T3-E1 (Fig. 6).

In conclusion, pretreatment with LY, API, Rapa upregulated the autophagy and apoptosis, led to cell cycle arrest, but the cell proliferation was still maintained. That's a little confusing. In addition to the protective effect of autophagy on cell survival, there maybe exist some other proliferative mechanisms that need to be further studied and discovered. 


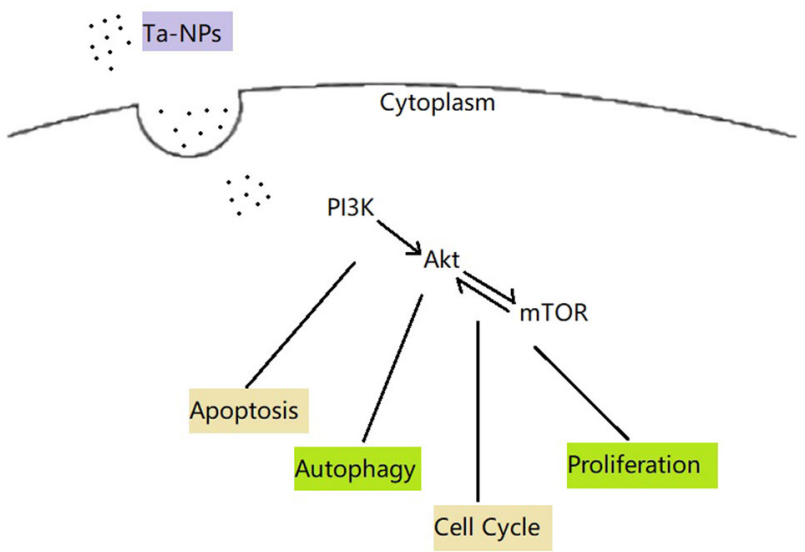

Fig. 6 Schematic diagram of the Ta-NPs induced effects on MC3T3E1. Note: Ta-NPs are endocytosed and activated the mTOR signaling pathway to induce apoptosis, regulate autophagy, cell cycle, and cell proliferation. Ta-NPs Tantalum nanoparticles

\section{Conclusion}

The Akt/mTOR signaling pathway as well as its feedback loop was involved in Ta-NPs induced autophagy and proliferation. However, further research is needed to elucidate the exact signal molecule involved in the Akt/mTOR feedback loop.

Funding This work was supported by the Natural Science Foundation of Guangdong Province (2018A030310402), the Guangdong Medical Research Foundation (B2018055).

\section{Compliance with ethical standards}

Conflict of interest The authors declare no competing interests.

Publisher's note Springer Nature remains neutral with regard to jurisdictional claims in published maps and institutional affiliations.

Open Access This article is licensed under a Creative Commons Attribution 4.0 International License, which permits use, sharing, adaptation, distribution and reproduction in any medium or format, as long as you give appropriate credit to the original author(s) and the source, provide a link to the Creative Commons license, and indicate if changes were made. The images or other third party material in this article are included in the article's Creative Commons license, unless indicated otherwise in a credit line to the material. If material is not included in the article's Creative Commons license and your intended use is not permitted by statutory regulation or exceeds the permitted use, you will need to obtain permission directly from the copyright holder. To view a copy of this license, visit http://creativecommons. org/licenses/by/4.0/.

\section{References}

1. Wang F, Wang L, Feng Y, Yang X, Ma Z, Shi L, et al. Evaluation of an artificial vertebral body fabricated by a tantalum-coated porous titanium scaffold for lumbar vertebral defect repair in rabbits. Sci Rep. 2018;8:8927 https://doi.org/10.1038/s41598018-27182-x

2. Wang L, Hu X, Ma X, Ma Z, Zhang Y, Lu Y, et al. Promotion of osteointegration under diabetic conditions by tantalum coatingbased surface modification on 3-dimensional printed porous titanium implants. Colloids Surf B Biointerfaces. 2016;148:440-52. https://doi.org/10.1016/j.colsurfb.2016.09.018

3. Lu RJ, Wang X, He HX, E LL, Li Y, Zhang GL, et al. Tantalumincorporated hydroxyapatite coating on titanium implants: its mechanical and in vitro osteogenic properties. J Mater Sci Mater Med. 2019;30:111 https://doi.org/10.1007/s10856-019-6308-9

4. Wang Q, Qiao Y, Cheng M, Jiang G, He G, Chen Y, et al. Tantalum implanted entangled porous titanium promotes surface osseointegration and bone ingrowth. Sci Rep. 2016;6:26248 https://doi.org/10.1038/srep26248

5. Ding D, Xie Y, Li K, Huang L, Zheng X. Micro/Nano structural tantalum coating for enhanced osteogenic differentiation of human bone marrow stem cells. Materials (Basel). 2018;11. https://doi. org/10.3390/ma11040546.

6. Wang H, Su K, Su L, Liang P, Ji P, Wang C. Comparison of 3Dprinted porous tantalum and titanium scaffolds on osteointegration and osteogenesis. Mater Sci Eng C Mater Biol Appl. 2019;104:109908 https://doi.org/10.1016/j.msec.2019.109908

7. Kang C, Wei L, Song B, Chen L, Liu J, Deng B, et al. Involvement of autophagy in tantalum nanoparticle-induced osteoblast proliferation. Int J Nanomed. 2017;12:4323-33. https://doi.org/10. 2147/IJN.S136281

8. Ruckh T, Porter JR, Allam NK, Feng X, Grimes CA, Popat KC. Nanostructured tantala as a template for enhanced osseointegration. Nanotechnology. 2009;20:045102 https://doi.org/10.1088/ 0957-4484/20/4/045102

9. Tran PA, Fox K, Tran N. Novel hierarchical tantalum oxidePDMS hybrid coating for medical implants: One pot synthesis, characterization and modulation of fibroblast proliferation. $\mathbf{J}$ Colloid Interface Sci. 2017;485:106-15. https://doi.org/10.1016/j. jcis.2016.06.048

10. Huo WT, Zhao LZ, Yu S, Yu ZT, Zhang PX, Zhang YS. Significantly enhanced osteoblast response to nano-grained pure tantalum. Sci Rep. 2017;7:40868 https://doi.org/10.1038/ srep40868

11. Moon BS, Kim S, Kim HE, Jang TS. Hierarchical micro-nano structured Ti6Al4V surface topography via two-step etching process for enhanced hydrophilicity and osteoblastic responses. Mater Sci Eng C Mater Biol Appl. 2017;73:90-8. https://doi.org/ 10.1016/j.msec.2016.12.064

12. Dou X, Wei X, Liu G, Wang S, Lv Y, Li J, et al. Effect of porous tantalum on promoting the osteogenic differentiation of bone marrow mesenchymal stem cells in vitro through the MAPK/ERK signal pathway. J Orthop Transl. 2019;19:81-93. https://doi.org/ 10.1016/j.jot.2019.03.006

13. Lu M, Xu S, Lei ZX, Lu D, Cao W, Huttula M, et al. Application of a novel porous tantalum implant in rabbit anterior lumbar spine fusion model: in vitro and in vivo experiments. Chin Med J (Engl). 2019;132:51-62. https://doi.org/10.1097/CM9.0000000000000030

14. Wei X, Zhao D, Wang B, Wang W, Kang K, Xie H, et al. Tantalum coating of porous carbon scaffold supplemented with autologous bone marrow stromal stem cells for bone regeneration in vitro and in vivo. Exp Biol Med (Maywood). 2016;241:592-602. https://doi.org/10.1177/1535370216629578

15. Fu WM, Yang L, Wang BJ, Xu JK, Wang JL, Qin L, et al. Porous tantalum seeded with bone marrow mesenchymal stem cells attenuates steroid-associated osteonecrosis. Eur Rev Med Pharm Sci. 2016;20:3490-9.

16. Wang P, Qiao P, Xing H, Zhang R, Lingling E, Liu H. Cytotoxicity, oxidative stress, and autophagy effects of tantalum nanoparticles on MC3T3-E1 mouse osteoblasts. J Nanosci 
Nanotechnol. 2020;20:1417-24. https://doi.org/10.1166/jnn.2020. 17158

17. Shao X, Lai D, Zhang L, Xu H. Induction of autophagy and apoptosis via PI3K/AKT/TOR pathways by Azadirachtin A in spodoptera litura cells. Sci Rep. 2016;6:35482 https://doi.org/10. 1038/srep35482

18. Fan XJ, Wang Y, Wang L, Zhu M. Salidroside induces apoptosis and autophagy in human colorectal cancer cells through inhibition of PI3K/Akt/mTOR pathway. Oncol Rep. 2016;36:3559-67. https://doi.org/10.3892/or.2016.5138

19. Klionsky DJ, Abdelmohsen K, Abe A, Abedin MJ, Abeliovich H, Acevedo Arozena A, et al. Guidelines for the use and interpretation of assays for monitoring autophagy (3rd edition). Autophagy. 2016;12:1-222. https://doi.org/10.1080/15548627.2015.1100356

20. Jiang YQ, Kou JY, Han XB, Li XS, Zhong ZY, Liu ZN et al. ROS-dependent activation of autophagy through the PI3K/Akt/ mTOR pathway is induced by hydroxysafflor yellow A-Sonodynamic therapy in THP-1 macrophages. Oxid Med Cell Longev. 2017. https://doi.org/10.1155/2017/8519169.

21. Wang SSS, Chen YHH, Chen N, Wang LJJ, Chen DXX, Weng HLL et al. Hydrogen sulfide promotes autophagy of hepatocellular carcinoma cells through the PI3K/Akt/mTOR signaling pathway. Cell Death Dis. 2017;8. https://doi.org/10.1038/Cddis.2017.18.

22. Veilleux A, Houde VP, Bellmann K, Marette A. Chronic inhibition of the mTORC1/S6K1 pathway increases insulin-induced PI3K activity but inhibits Akt2 and glucose transport stimulation in 3T3-L1 adipocytes. Mol Endocrinol. 2010;24:766-78. https:// doi.org/10.1210/me.2009-0328

23. Maity S, Das F, Ghosh-Choudhury N, Kasinath BS, Ghosh Choudhury G. High glucose increases miR-214 to power a feedback loop involving PTEN and the Akt/mTORC1 signaling axis. FEBS Lett. 2019;593:2261-72. https://doi.org/10.1002/1873-3468.13505

24. Galoian K, Temple HT, Galoyan A. mTORC1 inhibition and ECM-cell adhesion-independent drug resistance via PI3K-AKT and PI3K-RAS-MAPK feedback loops. Tumour Biol. 2012;33:885-90. https://doi.org/10.1007/s13277-011-0315-x

25. Liu B, Luo C, Zheng Z, Xia Z, Zhang Q, Ke C, et al. Shengui Sansheng San extraction is an angiogenic switch via regulations of AKT/mTOR, ERK1/2 and Notch1 signal pathways after ischemic stroke. Phytomedicine. 2018;44:20-31. https://doi.org/10.1016/j. phymed.2018.04.025

26. Bernard M, Yang B, Migneault F, Turgeon J, Dieude M, Olivier MA et al. Autophagy drives fibroblast senescence through MTORC2 regulation. Autophagy. 2020:1-13. https://doi.org/10. 1080/15548627.2020.1713640.

27. Jhanwar-Uniyal M, Gillick JL, Neil J, Tobias M, Thwing ZE, Murali R. Distinct signaling mechanisms of mTORC1 and mTORC2 in glioblastoma multiforme: A tale of two complexes. Adv Biol Regul. 2015;57:64-74. https://doi.org/10.1016/j.jbior. 2014.09.004
28. Zhang H, Yan S, Khambu B, Ma F, Li Y, Chen X, et al. Dynamic MTORC1-TFEB feedback signaling regulates hepatic autophagy, steatosis and liver injury in long-term nutrient oversupply. Autophagy. 2018;14:1779-95. https://doi.org/10.1080/15548627. 2018.1490850

29. Nie SD, Li X, Tang CE, Min FY, Shi XJ, Wu LY, et al. High glucose forces a positive feedback loop connecting ErbB4 expression and $\mathrm{mTOR} / \mathrm{S} 6 \mathrm{~K}$ pathway to aggravate the formation of tau hyperphosphorylation in differentiated SH-SY5Y cells. Neurobiol Aging. 2018;67:171-80. https://doi.org/10.1016/j. neurobiolaging.2018.03.023

30. Dalle Pezze P, Sonntag AG, Thien A, Prentzell MT, Godel M, Fischer $\mathrm{S}$, et al. A dynamic network model of mTOR signaling reveals TSC-independent mTORC2 regulation. Sci Signal. 2012;5:ra25 https://doi.org/10.1126/scisignal.2002469

31. Singh G, Akcakanat A, Sharma C, Luyimbazi D, Naff KA, Meric-Bernstam F. The effect of leucine restriction on Akt/mTOR signaling in breast cancer cell lines in vitro and in vivo. Nutr Cancer. 2011;63:264-71. https://doi.org/10.1080/01635581.2011. 523504

32. He X, Wang Y, Zhu J, Orloff M, Eng C. Resveratrol enhances the anti-tumor activity of the mTOR inhibitor rapamycin in multiple breast cancer cell lines mainly by suppressing rapamycin-induced AKT signaling. Cancer Lett. 2011;301:168-76. https://doi.org/10. 1016/j.canlet.2010.11.012

33. Fourneaux B, Chaire V, Lucchesi C, Karanian M, Pineau R, Laroche-Clary A, et al. Dual inhibition of the PI3K/AKT/mTOR pathway suppresses the growth of leiomyosarcomas but leads to ERK activation through mTORC2: Biological and clinical implications. Oncotarget. 2017;8:7878-90. https://doi.org/10. 18632/oncotarget.13987

34. Soares HP, Ming M, Mellon M, Young SH, Han L, Sinnet-Smith $\mathrm{J}$, et al. Dual PI3K/mTOR inhibitors induce rapid overactivation of the MEK/ERK pathway in human pancreatic cancer cells through suppression of mTORC2. Mol Cancer Ther. 2015;14:1014-23. https://doi.org/10.1158/1535-7163.MCT-140669

35. Yang G, Murashige DS, Humphrey SJ, James DE. A positive feedback loop between Akt and mTORC2 via SIN1 phosphorylation. Cell Rep. 2015;12:937-43. https://doi.org/10.1016/j. celrep.2015.07.016

36. Ye L, Varamini B, Lamming DW, Sabatini DM, Baur JA. Rapamycin has a biphasic effect on insulin sensitivity in $\mathrm{C} 2 \mathrm{C} 12$ myotubes due to sequential disruption of mTORC1 and mTORC2. Front Genet. 2012;3:177 https://doi.org/10.3389/fgene.2012. 00177

37. Chen XG, Liu F, Song XF, Wang ZH, Dong ZQ, Hu ZQ, et al. Rapamycin regulates Akt and ERK phosphorylation through mTORC1 and mTORC2 signaling pathways. Mol Carcinog. 2010;49:603-10. https://doi.org/10.1002/mc.20628 